\title{
Pengaruh Titik Didih Solvent Terhadap Nilai Transfer Efficiency (TE) Proses Pengecatan Atomisasi
}

\author{
Nur Islahudin ${ }^{1 *}$, Helmy Rahadian ${ }^{2}$, Pramudi Arsiwi ${ }^{3}$ \\ 1,3Program Studi Teknik Industri, Universitas Dian Nuswantoro \\ ${ }^{2}$ Program Studi Teknik Elektro, Universitas Dian Nuswantoro \\ Jl. Imam Bonjol No.207, Pendrikan Kidul, Kec. Semarang Tengah, Kota Semarang, Jawa Tengah 50131 \\ *E-mail: nur.islahudin@dsn.dinus.ac.id
}

Received: 08-01-2020; Accepted: 16-04-2020; Published online: 23-04-2020

\begin{abstract}
Abstrak
Paper ini ingin mengetahui pengaruh titik didih solvent dari komponen material cat terhadap nilai transfer efficiency (TE) proses pengecatan menggunakan spray atomisasi pada pengecatan produk berbahan plastik. Pemilihan jenis solvent saat ini masih berorientasi pada harga dan kemampuan melarutkan solvent terhadap material cat. Dalam aplikasi proses pengecatan selain membutuhkan daya larut, material cat harus dapat menghasilkan kualitas spray atau atomisasi yang baik saat proses pengecatan. Atomisasi pengecatan yang baik dapat dilihat dari jumlah overspray yang terjadi saat proses pengecatan. Overspray yang terjadi pada proses pengecatan akan mempengaruhi kualitas hasil dari proses pengecatan. Salah satu cara untuk menghitung overspray proses pengecatan dapat dilakukan dengan cara mengukur nilai transfer efisiensi dari proses pengecatan. Nilai TE merupakan cara untuk menghitung jumlah material cat yang melapisi permukaan produk dibandingkan dengan jumlah total material cat yang dibutuhkan untuk proses pengecatan sehingga jumlah overspray dapat diketahui dari hasil pengukuran nilai TE. Salah satu parameter dari solvent yang sangat erat hubungan nya dengan overspray adalah titik didih solvent. Dari hasil pengujian awal diperoleh bahwa solvent butyl acetate dan butyl cellocove mempunyai daya larut (solubility) baik terhadap jenis cat Nitrocellulose (NC). Hasil pengujian destilasi dua jenis solvent menunjukan bahwa butyl acetate mempunyai nilai titik didih rendah dan butyl cellosove mempunyai titik didih medium. Selanjutnya hasil perhitungan nilai TE kedua jenis solvent ini diperoleh hasil bahwa solvent butyl cellosove mempunyai nilai TE lebih baik (20,2\%) dibandingkan nilai TE solvent butyl acetate $(16,0 \%)$. Hal ini menunjukan bahwa solvent dengan titik didih medium mempunyai nilai TE yang lebih baik dari solvent dengan titik didih rendah.
\end{abstract}

Kata kunci: Atomisasi; Solvent; Transfer Efisiensi

\begin{abstract}
This paper wants to find out the effect of the solvent boiling point of the paint material component on the value of the transfer efficiency (TE) of the painting process using atomizing spray-on painting products made from plastic. The choice of the type of solvent is still oriented to the price and the ability to dissolve the solvent against the paint material. In the application process of painting in addition to requiring solubility, the paint material must be in a position to produce good quality spray or atomization during the painting process. Good atomization of painting can be seen from the amount of over spray that occurs during the painting process. Over spray that occurs in the painting process will affect the quality of the results of the painting process. One way to calculate the over spray of the painting process can be done by measuring the transfer value of the efficiency of the painting process. The TE value is a way to calculate the amount of paint material that coats the product surface compared to the total amount of paint material needed for the painting process so that the amount of over spray can be known from the measurement results of the TE value. One of the parameters of a solvent that is very closely related to over spray is the boiling point of the solvent. From the preliminary test results, it was found that the type of solvent butyl acetate and butyl cellocove have good solubility to the type of paint Nitrocellulose (NC). Distillation test results of two types of solvent show that acetate has a low boiling point and butyl cellosove has a medium boiling point. Furthermore, the results of the calculation of the TE values Of these two types of solvents showed that the solvent butyl cellosove had a better TE value (20.2\%) than the TE value of the solvent Butyl acetate (16.0\%). This shows that the medium boiling solvent has a better TE value than the low boiling solvent.
\end{abstract}

Keywords: Atomization; Solvent;Transfer Efficiency

\section{Pendahuluan}

Green manufacturing merupakan salah satu konsep sistem produksi yang mengedapankan perbaikan dalam hal pemakaian material, penggunaan energi untuk produksi serta pemanfaatan bahan ramah lingkungan untuk kegiatan 
produksi suatu industri manufaktur [1]. Konsep sistem produksi ini terus mengalami perkembangan sampai ke semua lini bagian produksi dari suatu industri manufaktur. Salah satu industri manufaktur yang sudah atau sedang menjalankan konsep ini adalah industri otomotif.

Industri otomotif di Indonesia mengalami pertumbuhan produksi yang cukup signifikan setiap tahunnya. Hal ini dapat dilihat dari data AISI (Asosiasi Industri Sepeda motor Indonesia) dan Gaikindo (Gabungan Industri Kendaraan Bermotor Indonesia) yang menunjukan pertumbuhan produksi otomotif setiap tahun baik dari sepedamotor maupun dari automobile. Salah satu industri otomotif yang mengalami perubahan jumlah produksi yang cukup pesat adalah industri perakitan sepedamotor. Dalam industri perkaitan sepedamotor terdapat beberapa proses manufaktur yang sangat erat kaitannya dalam hal penerapan konsep dari green manufacturing. Salah satu proses produksi dari industri manufaktur yang mempunyai kaitan erat dengan konsep green manufacturing adalah proses pengecatan produk berbahan plastik (painting plastic).

Engine Product

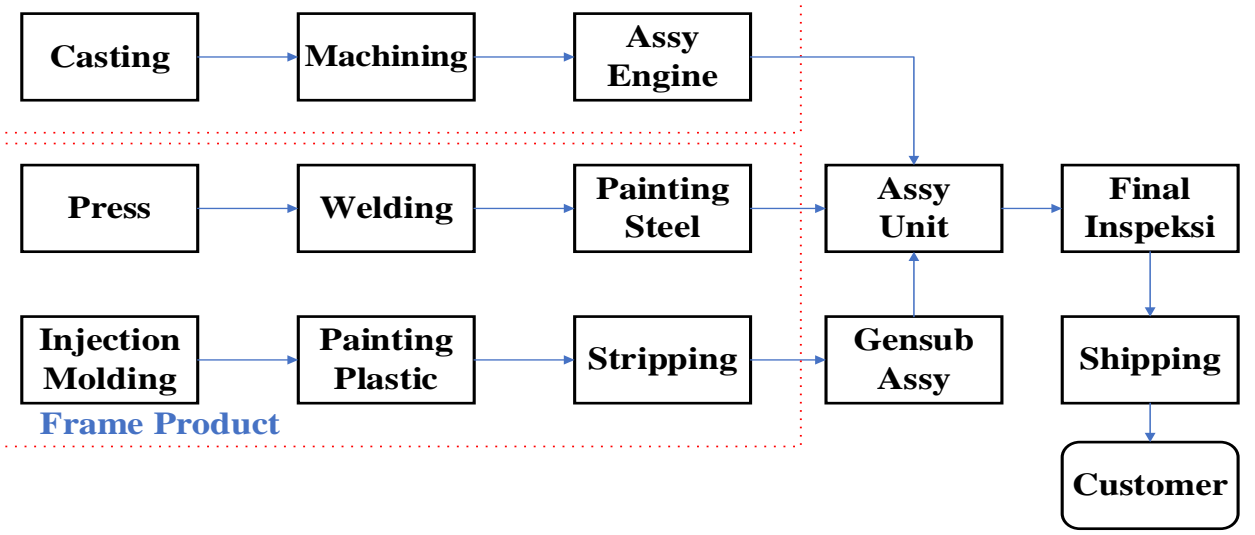

Gambar 1. Proses Manufaktur Industri Perakitan Sepeda Motor

Dalam proses pengecatan dalam industri otomotif terdapat beberapa hal yang berkaitan dengan green manufacturing antara lain pemakaian material cat yang digunakan untuk industri otomotif mewakili $50 \%$ dari total ongkos produksi yang dibutuhkan oleh bagian pengecatan [2]. Oleh karena itu bagian painting plastic di industri perakitan sepedamotor menjadikan pemakaian material cat sebagai salah satu parameter control dalam kegiatan produksinya [3]. Selain ongkos material, nilai transfer efisiensi proses pengecatan pada bagian painting plastic masih cukup rendah karena adanya material cat yang terbuang saat proses pengecatan (over spray). Nilai transfer efisiensi proses painting plastic berkisar antara 20\% - 30\% [4]. Hal ini menunjukan bahwa material cat yang menempel produk hanya berkisar (20-30)\% dan material yang terbuang sebesar (70-80)\% dari total pemakaian material cat yang digunakan untuk pengecatan suatu produk. Material cat yang terbuang akibat overspray proses pengecatan akan menjadi limbah yang berdampak pada nilai volatile organic compound (VOC). Nilai VOC merupakan salah satu parameter untuk melihat berapa besar material yang digunakan dalam suatu proses pengecatan yang terbuang ke udara bebas, semakin banyak material yang terbuang akan berdampak terhadap global warming [5].

Perbaikan tentang nilai transfer efisiensi pada proses pengecatan dapat dilakukan dengan cara mencari setting parameter optimal dari spray gun. Penggunaan jenis airless spray gun dapat meningkatkan nilai transfer efisiensi proses pengecatan [6]. Namun terdapat permasalahan apabila jenis airless spray gun digunakan untuk pengecatan dengan kondisi kapasitas yang cukup tinggi seperti proses produksi pada industri perakitan sepedamotor. Operator spray akan mengalami 
kesulitan untuk proses pengecatan dengan jenis spray gun ini apabila kapasitas produksi cukup tinggi [7]. Penggunaan jenis spray gun ini harus di ikuti dengan perbaikan dari segi material. Hal ini disebabkan karena hasil nilai transfer efisiensi optimal dapat diperoleh dengan kombinasi antara penggunaan jenis spray gun dan material yang digunakan.Penelitian ini ingin mengetahui pengaruh material cat terhadap nilai transfer efisiensi proses pengecatan. Material cat yang digunakan untuk proses pengecatan terdiri dari beberapa komponen [8] [9] yaitu resin, pigment, additive, solvent, yang dapat dilihat pada Gambar 2.

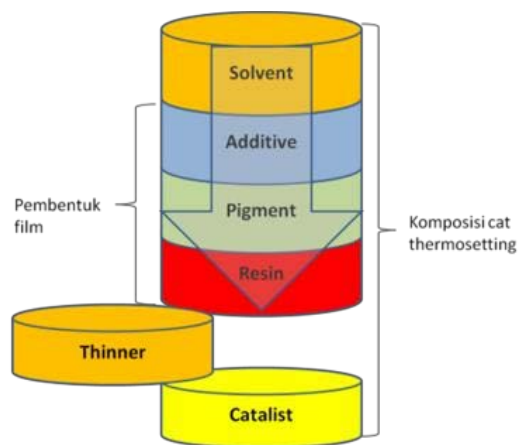

Gambar 2. Komposisi Material Cat

Salah satu komponen material cat yang dapat mempengaruhi nilai transfer efisiensi material adalah komponen solvent. Saat proses atomisasi solvent mempunyai peran untuk menjaga kondisi butiran hasil atomisasi dalam kondisi basah. Apabila hasil atomisasi dalam kondisi kering partikel cat tidak dapat menempel pada produk berbahan plastik. Partikel cat yang tidak menempel akan menjadi overspray material cat proses pengecatan. Salah satu parameter dari solvent yang dapat mempengaruhi kondisi hasil atomisasi adalah titik didih [10]. Semakin tinggi nilai boiling point suatu solvent semakin lama solvent itu untuk menguap yang berarti solvent akan dijaga untuk tidak menguap saat proses atomisasi dan sebaliknya. Jadi nilai boiling point solvent dapat digunakan sebagai parameter untuk mengetahui kualitas dari atomisasi yang berdampak terhadap nilai transfer efisiensi proses pengecatan.

Solvent untuk material cat umumnya terdiri dari beberapa jenis kelompok antara lain alcohol, aromatic hydrocarbon, ether dan kethone [11] Solvent dalam proses pembuatan cat dapat digunakan sebagai pelarut saat proses pencampuran komponen-komponen pembentuk material cat. Selain untuk pelarut solvent juga mempunyai peranan untuk penentuan kualitas atomisasi proses pengecatan. Oleh karena itu pemilihan solvent untuk proses pengecatan mempunyai dua peranan yaitu sebagai pelarut dan kualitas atomisasi yang berdampak terhadap overspray proses pengecatan.

\section{Metode Penelitian}

Penelitian ini menggunakan metode eksperimen pada salah satu jenis material cat yaitu jenis Nitrocellulose (NC). Penelitian ini dilakukan melalui beberapa tahap yang dapat dilihat pada Gambar 3.

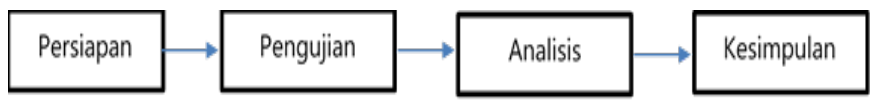

Gambar 3. Tahapan Penelitian

\section{Tahap persiapan:}

Pada tahap ini mempersiapkan beberapa hal terkait dengan material cat dan solvent, peralatan yang digunakan untuk pengujian seperti oven, spray gun, kompresor, timbangan digital serta test piece untuk pengujian. 
Tahap pengujian:

Pengujian dalam penelitian ini dibagi menjadi tiga tahap antara lain tahap pengujian daya larut solvent dan destilasi solvent, pengujian non volatile cat dan pengujian nilai transfer efisiensi dari proses pengecatan.

\section{Tahap Analisis:}

Untuk melihat pengaruh dari nilai titik didih solvent terhadap nilai transfer efisiensi metode analisis yang digunakan dalam penelitian ini adalah metode analysis of variance (ANOVA).

\section{Kesimpulan:}

Tahap ini menjelaskan hasil akhir dari pengujian yang telah dilakukan.

Pengujian awal yang dilakukan adalah pengujian untuk mengetahui daya larut (solubility) beberapa jenis solvent. Pengujian ini dilakukan untuk mengetahui solvent jenis apa yang baik digunakan untuk pelarut pada material cat jenis NC. Metode pengujian yang dilakukan adalah dengan melakukan pencampuran material cat dan solvent kemudian di ukur nilai viscositasnya. Nilai perbandingan yang digunakan untuk pengujian ini adalah (1:0,7) Dari hasil pengujian jenis solvent Butyl acetate (BA), Butyl Cellosove (BC) dan Cyclohexanol (CYC) mempunyai daya larut yang baik. Hasil pengujian selengkapnya dapat dilihat pada Tabel 1

Tabel 1. Solubility jenis-jenis solvent

\begin{tabular}{cccc}
\hline No & Solvent & Solubility & Viscositas \\
\hline $\mathbf{1}$ & Xylene & Tidak baik & Cat menggumpal \\
$\mathbf{2}$ & Butyl Acetate $(B A)$ & Baik & 28,84 \\
$\mathbf{3}$ & Butyl Cellosove (BC) & Baik & $40,45^{\prime}$ \\
$\mathbf{4}$ & Pegasol 150 & Tidak baik & Cat menggumpal \\
$\mathbf{5}$ & Cyclohexanol (CYC) & Baik & 25,6 \\
\hline
\end{tabular}

Selain pengujian daya larut pengukuran nilai titik didih solvent akan digunakan sebagai pertimbangan untuk pemilihan jenis solvent yang akan digunakan untuk pengujian terhadap nilai transfer efisiensi. Berikut ini hasil pengujian destilasi beberapa jenis solvent yang dapat dilihat pada Gambar 4.

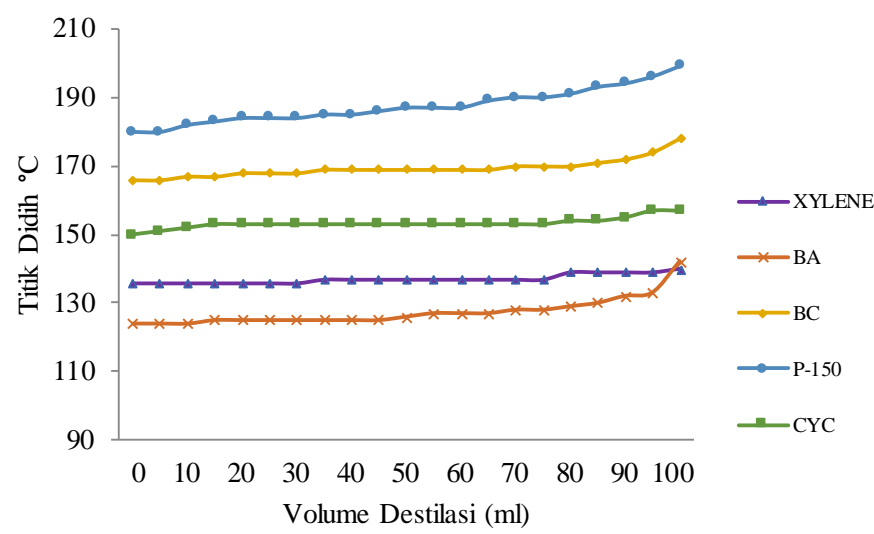

Gambar 4. Grafik destilasi solvent

Dari dua pengujian daya larut dan titik didih solvent, terdapat tiga solvent yang dapat digunakan untuk pengujian pengukuran nilai transfer efisiensi proses pengecatan. Namun untuk jenis solvent cyclohexanol tidak dapat digunakan karena jenis solvent ini bersifat destructive pada peralatan dan juga fisik operator yang memegang nya, sehingga solvent 
yang digunakan untuk pengujian nilai transfer efisiensi adalah BA dan BC. Kedua solvent ini mempunyai nilai titik didih yang berbeda sehingga dapat digunakan untuk pembanding pengujian pengaruh titik didih solvent terhadap nilai transfer efisiensi proses pengecatan.

\subsection{Perhitungan Nilai TE}

Perhitungan nilai TE proses pengecatan diperoleh dari perbandingan antara pemakaian material cat yang digunakan untuk proses pengecatan dengan berat akhir cat yang menempel di produk. Perhitungan nilai TE dapat dilihat pada Persamaan 1.

$$
T E=\frac{\left(m_{a}-m_{b}\right)}{m_{c}} \times 100 \%
$$

Dimana TE adalah nilai transfer efisiensi proses pengecatan merupakan perbandingan antara jumlah material yang melapisi produk dengan jumlah total pemakaian material cat yang digunakan untuk proses pengecatan produk, $m_{a}$ adalah gabungan berat material cat hasil pengecatan dan berat test piece yang digunakan untuk proses pengecatan dimana pengukuran berat dilakukan pada saat cat masih dalam kondisi basah, $m_{b}$ merupakan berat test piece yang digunakan untuk eksperimen bahan test piece yang digunakan adalah acrylic dengan ukuran $(150 \times 100 \times 3) \mathrm{mm}$ sedangkan $m_{c}$ adalah berat cat yang dibutuhkan untuk pengecatan satu test piece. Pengukuran dilakukan dengan mengukur selisih berat material cat yang ada pada cane spray gun sebelum proses pengecatan dan setelah proses pengecatan.

\subsection{Analisis ANOVA}

Setelah diperoleh hasil nilai TE dari masing-masing jenis solvent, pengujian selanjutnya adalah pengujian ANOVA Analisis ANOVA digunakan untuk mengetahui apakah ada perbedaan yang signifikan antara hasil perhitungan nilai TE dari dua jenis solvent yang digunakan untuk proses pengecatan. Selain itu analisis ANOVA di unakan untuk melihat apakah ada pengaruh dari dua jenis solvent ini terhadap nilai transfer efisiensi proses pengecatan kedua solvent tersebut dengan melihat nilai $\mathrm{R}^{2}$ dari hasil pengujian ANOVA.

\section{Hasil dan pembahasan}

Dari pengukuran TE yang telah dilakukan pada dua jenis solvent yaitu BA dan BC diperoleh nilai TE masing-masing solvent yang ditampilkan pada Tabel 2 dan Tabel 3, dan pada Gambar 5 ditampilkan Perbedaan Nilai Transfer Efisiensi.

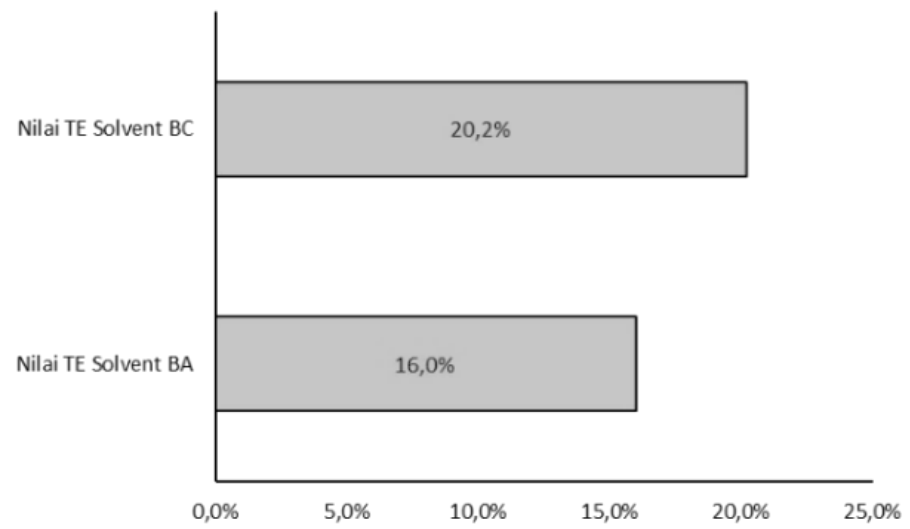

Gambar 5. Perbedaan Nilai Transfer Efisiensi Pengecatan Dengan BA Dan BC 
Nur Islahudin, dkk./Jurnal Rekayasa Mesin

p-ISSN: 1411-6863, e-ISSN: 2540-7678

Vol.15|No.1|51-58|April|2020

Tabel 2. Hasil Perhitungan Transfer Efisensi Pengecatan Dengan Jenis Solvent Butyl Acetate

\begin{tabular}{ccccc}
\hline No & $\boldsymbol{m}_{\boldsymbol{b}}(\mathrm{gr})$ & $\boldsymbol{m}_{\boldsymbol{a}}(\mathrm{gr})$ & $\boldsymbol{m}_{\boldsymbol{c}}(\mathrm{gr})$ & $\mathrm{TE}$ \\
\hline 1 & 44,05 & 44,38 & 2,22 & $15,1 \%$ \\
\hline 2 & 44,05 & 44,39 & 2,22 & $15,2 \%$ \\
\hline 3 & 44,05 & 44,40 & 2,22 & $15,9 \%$ \\
\hline 4 & 44,06 & 44,46 & 2,22 & $17,9 \%$ \\
\hline 5 & 44,04 & 44,40 & 2,22 & $16,0 \%$ \\
\hline 6 & 44,05 & 44,42 & 2,22 & $14,8 \%$ \\
\hline 7 & 44,05 & 44,36 & 2,22 & $16,1 \%$ \\
\hline 9 & 44,06 & 44,42 & 2,22 & $16,6 \%$ \\
\hline 10 & 44,05 & 44,42 & 2,22 & $16,3 \%$
\end{tabular}

Tabel 3. Hasil Perhitungan Transfer Efisiensi Pengecatan Dengan Jenis Solvent Butyl Cellosove

\begin{tabular}{ccccc}
\hline No & $\boldsymbol{m}_{\boldsymbol{b}}(\mathrm{gr})$ & $\boldsymbol{m}_{\boldsymbol{a}}(\mathrm{gr})$ & $\boldsymbol{m}_{\boldsymbol{c}}$ (gr) & $\mathrm{TE}$ \\
\hline 1 & 44,05 & 44,38 & 2,22 & $15,1 \%$ \\
\hline 2 & 44,05 & 44,39 & 2,22 & $15,2 \%$ \\
\hline 3 & 44,05 & 44,40 & 2,22 & $15,9 \%$ \\
\hline 4 & 44,06 & 44,46 & 2,22 & $17,9 \%$ \\
\hline 5 & 44,04 & 44,40 & 2,22 & $16,0 \%$ \\
\hline 6 & 44,05 & 44,42 & 2,22 & $16,8 \%$ \\
\hline 7 & 44,05 & 44,36 & 2,22 & $14,1 \%$ \\
\hline 9 & 44,06 & 44,42 & 2,22 & $16,1 \%$ \\
\hline 10 & 44,05 & 44,42 & 2,22 & $16,6 \%$ \\
\hline
\end{tabular}

\section{Analisis ANOVA}

Dari hasil perhitungan yang sudah dilakukan diketahui bahwa nilai F hitung (table 4) mempunyai nilai lebih besar dari nilai F Tabel dari perhitungan excel, maka hipotesa H0 ditolak yang berarti terdapat perbedaan hasil transfer efisiensi dari dua sampel solvent.

Tabel 4. Hasil perhitungan pada ANOVA

\begin{tabular}{ccccc}
\hline Sumber Variasi & Jumlah Kuadrat & $\begin{array}{c}\text { Derajat } \\
\text { Bebas }\end{array}$ & Perkiraan varian & F hitung \\
\cline { 1 - 4 } Antar Kelompok (SSB) & 0,0080 & 1 & $M S_{B}=\frac{0,0080}{1}=0,0080$ & $\frac{0,0080}{0,00022}=36$ \\
\hline $\begin{array}{c}\text { Di dalam } \\
\text { Kelompok(SSW) }\end{array}$ & 0,0040 & 18 & $M S_{W}=\frac{0,0040}{18}=0,00022$ & \\
\hline Total & 0,0120 & 19 & &
\end{tabular}

$\mathrm{S}=0,01491 \quad \mathrm{R}-\mathrm{Sq}=66,67 \% \quad \mathrm{R}-\mathrm{Sq}(\mathrm{adj})=64,81 \%$

Hasil pengujian ANOVA menunjukan selain adanya perbedaan hasil nilai transfer efisiensi proses pengecatan dari dua jenis solvent juga dapat dilihat nilai $\mathrm{R}^{2}$ sebesar 66,67\% yang berarti bahwa adanya pengaruh antara dua jenis solvent 
yang diujikan. Nilai $\mathrm{R}^{2}$ menunjukan bahwa adanya pengaruh hasil TE solvent jenis BA terhadap hasil TE solvent BC sebesar 66,67\%. Untuk proses pengecatan menggunakan material cat dengan solvent BA mempunyai nilai transfer efisiensi sebesar $16 \%$ yang berarti dari total pemakaian material yang digunakan untuk pengecatan hanya $16 \%$ yang menempel ke produk sedangkan untuk material dengan solvent BC mempunyai nilai TE lebih baik yaitu 20,2\%. Material cat yang menggunakan solvent jenis BA mempunyai nilai TE lebih rendah dibandingkan dengan material yang menggunakan solvent BC. Hal ini disebabkan karena beberapa hal anatara lain overspray yang diakibatkan sovlvent BA lebih besar daripada BC. Proses pengecatan yang menggunakan solvent BA atomisasi yang terjadi butirannya cukup besar dan kering ketika menempel di permukaan produk, sedangkan material jenis solvent BC menghasilkan atomisasi yang masih basah, sehingga partikel cat menempel ke permukaan produk masih dalam kondisi basah. Kondisi basahnya partikel cat ke permukaan produk disebabkan oleh nilai titik didih solvent penyusun komponen material cat. Untuk solvent BC mempunyai nilai titik didih yang cukup tinggi yaitu $\pm(166-168)^{\circ} \mathrm{C}$ sehingga partikel hasil atomisasi masih dalam kondisi basah saat proses atomisasi. Selain titik didih solvent nilai NV dari material cat juga mempengaruhi nilai transfer efisiensi dari proses pengecatan. Nilai NV merupakan padatan yang tidak menguap dari suatu material cat, hal ini dapat mempengaruhi nilai transfer efisiensi material cat karena apabila nilai NV tinggi, material cat yang menempel di produk akan tinggi juga.

Namun dalam aktual pemilihan jenis solvent selain didasarkan terhadap dua parameter yaitu solubility dan titik didih, pemilihan jenis solvent untuk pengecatan mempertimbangkan factor biaya, sehingga diperlukan kombinasi solvent yang menghasilkan biaya yang optimum untuk proses pengecatan.

\section{Kesimpulan}

Nilai transfer efisiensi dipengaruhi oleh beberapa faktor antara lain overspray proses pengecatan dan nilai NV dari material. Besarnya overspray dipengaruhi oleh titik didih solvent dari material yang digunakan sedangkan nilai NV dipengaruhi oleh solubility dari solvent tersebut. Semakin cepat nilai titik didih solvent yang digunakan untuk proses pengecatan akan menghasilkan proses atomisasi yang kurang baik sehingga berdampak terhadap overspray pengecatan. Beberapa jenis solvent yang baik digunakan untuk pencampuran material cat jenis NC (nitrocellulose) adalah Butyl Accetate dan Butyl Cellocove. Kedua jenis solvent ini mempunyai sifat penguapan dan pelarutan yang cukup baik dibandingkan dengan jenis solvent yang lain. Dari pengujian yang sudah dilaksanakan tentang transfer efisiensi proses pengecatan, diperoleh bahwa besarnya nilai transfer efisiensi proses pengecatan dengan dua jenis solvent yang mempunyai titik didih rendah dan titik didih sedang menghasilkan nilai TE yang berbeda yaitu 16,0\% untuk jenis solvent rendah dan 20,2 \% untuk jenis solvent medium. Hal ini berarti bahwa pengecatan menggunakan jenis solvent medium dapat meningkatkan nilai transfer efisiensi proses pengecatan. Nilai TE ini menunjukan bahwa jumlah overspray yang Oleh karena itu factor titik didih solvent dapat digunakan sebagai salah satu variable control untuk proses pengecatan.Namun optimum setting untuk seberapa besar penggunakan solvent yang digunakan untuk bahan campuran material cat diperlukan penelitian lanjutan tentang berapa persen komposisi solvent yang ideal yang digunakan agar menghasilkan proses atomisasi yang baik.

\section{Ucapan terima kasih}

Terima kasih kami tujukan kepada Lembaga Penelitian Dan Pengabdian Mayarakat (LPPM) Universitas Dian Nuswantoro Semarang yang telah mendanai kegiatan penelitian ini, sehingga penelitan ini dapat berjalan dengan lancar. 


\section{Daftar Pustaka}

[1] Deif, A.M. A system model for green manufacturing. Journal Clean Production. 2011 September; 19 (14): hal.1554.

[2] Akafuah N.K. Automotive Painting Technology Chapter :Automotive Paint Spray Characterization and Visualization. Dordrecht : Spinger: 2012. hal.121.

[3] R. Pujiono. Modul Pengetahuan Tentang Cat Teori Dan Aplikasi.Jakarta: PT ICI Paint; 2000 p.15-16.

[4] Colbert, S.A., Cairncross, R.A. A computer simulation for predicting electrostatic spray coating patterns. in Powder Technology. 2005 Maret; 151(1-3) : hal.77 .

[5] Kim, J., Park, K., Hwang, Y., Park, I. Sustainable manufacturing: A case study of the forklift painting process.International Journal Production Research. 2010 April; 48(10): hal.3062

[6] Plesniak, M.W., Sojka, P.E., Singh, A.K. Transfer efficiency for airless painting systems. Journal Coatings Technology Research. 2004 April; 1 (2): hal.137.

[7] Ye, Q., Shen, B., Tiedje, O., Domnick, J. Investigations of Spray Painting Processes Using an Airless Spray Gun.24th European Conference on Liquid Atomization and Spray Systems; 5-7 september 2011 Estoril, Portugal. 24thILASS-Europe:2011. hal.1

[8] Goldschmidt, A., Joachim-streitberger, H. BASF Handbook on Basics of Coating Technology 2nd revised edition. Hannover, Germany: Vincentz Network : 2003. hal. 28.

[9] Islahudin, N. Teknologi proses pengecatan menggunakan sistem atomisasi pada produk berbahan plastik di industri perakitan sepeda motor. SINTEK Jurnal MESIN Teknolologi. Univ. Muhammadiyah Jakarta. 2019 Juni; 13 (01): hal. 15-25.

[10] Weiss, K.D. Paint and coatings: A mature industri in transition. Progress in Polymer Science. 1997 Mei; 22(2): hal. 204 .

[11] Talbert, R. Paint Technology Handbook. Folrida, United States : Taylor \& Francis Group ; 2008 . hal. 71-73. 